Paulino, S.; Soethe, P. - Thomas Mann e a cena intelectual no Brasil

\title{
Thomas Mann e a cena intelectual no Brasil: encontros e desencontros
}

\author{
Sibele Paulino* \\ Paulo Soethe
}

\begin{abstract}
Thomas Mann's Brazilian origin, from his mother Julia da Silva Bruhns, made it possible for the adult writer to make contact with Brazilian or foreign intellectuals, connected to the cultural scene in Brazil. In the first group we find Gilberto Freyre, Sérgio Buarque de Holanda and Erico Verissimo. Living in Brazil, Karl Lustig-Prean (whom later returns to Europe), and the translator Herbert Caro, settled in Brazil. Also, the direct or indirect contact with thinkers and writers, such as Karl Loewenstein, Heinrich Eduard Jacob, Marte Brill and Stefan Zweig has played a part in bringing Thomas Mann closer to the Brazilian universe. This and other points of contact are described in the present article, which intends to diffuse documents and data long unpublished or unavailable, offering up-to-date approaches to Thomas Mann works, as well as indicating biographical and documental information related to the writer, regarding his relationship to Brazil.
\end{abstract}

Keywords: Thomas Mann and Brazil; Cultural relationship between Brazil and Germany; Intellectual scene in Getúlio Vargas Era.

Resumo: A origem brasileira de Thomas Mann, por parte de sua mãe, Julia da Silva Bruhns, deu ocasião, na maturidade do escritor, a seu contato com intelectuais brasileiros ou estrangeiros ligados à cena cultural do Brasil. No primeiro grupo, tem-se Gilberto Freyre, Sérgio Buarque de Holanda e Erico Verissimo. Residentes no Brasil, Karl Lustig-Prean, que posteriormente retornará à Europa, e o tradutor Herbert Caro, que se radica em definitivo no Brasil. Também o contato direto ou indireto com pensadores e escritores como Karl Loewenstein, Heinrich Eduard Jacob, Marte Brill e Stefan Zweig colaboraram para a aproximação de Thomas Mann ao universo brasileiro. Estes e outros pontos de contato são descritos no presente artigo, que pretende difundir dados e documentos há muito inacessíveis ou inéditos, no sentido de contribuir com abordagens atualizadas da obra de Thomas Mann e oferecer à pesquisa especializada a indicação de dados biográficos e documentais relacionados ao escritor, no que concerne à sua relação com o Brasil.

Palavras-chave: Thomas Mann e o Brasil; Relações culturais entre Brasil e Alemanha; Cena intelectual brasileira na Era Vargas

* Sibele Paulino é Mestranda do Programa de Pós-graduação em Letras (UFPR). Email: sibelepaulino@yahoo.com.br . Paulo A. Soethe é professor de Língua e Literatura Alemã na UFPR. Email: soethe@ufpr.br. A tradução das citações foram feitas pelos autores do artigo.

Pandaemonium germanicum 14/2009.2, p. 28-53 - www.fflch.usp.br/dlm/alemao/pandaemoniumgermanicum 
Paulino, S.; Soethe, P. - Thomas Mann e a cena intelectual no Brasil

\section{Introdução}

A brasileira Julia da Silva Bruhns, nascida em 1851 nas proximidades de Parati (RJ), passou, nestes últimos anos, a ocupar mais centralmente o lugar que lhe cabe na história cultural alemã. Após perder a mãe, Senhorinha Maria da Silva, a pequena Julia emigrou em 1858 para a cidade de Lübeck com seu pai alemão, Johann Ludwig Bruhns. Foi criada em um pensionato e desposou com dezessete anos, em 1869, um importante comerciante da cidade, Thomas Johann Heinrich Mann. Julia Mann ficou viúva em 1891; dois anos depois, mudou-se para a Baviera com seus filhos e filhas, onde pôde acompanhar as bem-sucedidas carreiras literárias de Thomas e Heinrich Mann ${ }^{1}$.

No imaginário autobiográfico e poético do escritor e intelectual Thomas Mann (1875-1955), que constitui objeto deste artigo, a origem exótica da mãe e de si mesmo está presente de maneira discreta e cifrada. Em seus escritos, são raras e pontuais as figurações ficcionais da mãe e remissões diretas ao processo de aculturação vivido por ela. Daí compreender-se que a crítica especializada, até meados dos anos 1990, quando emergiram com força temas como a alteridade e as diferenciações e trânsitos culturais, não tenha dedicado grande atenção a essa dimensão da obra do escritor. ${ }^{2}$

De qualquer modo, no entanto, em razão da origem brasileira, que aguçou a curiosidade e provocou rechaço de alguns no Brasil e na Alemanha, o escritor acabou mesmo por estabelecer certa relação com o país em que nasceu sua mãe, não apenas por circunstâncias biográficas como os raros contatos com parentes ${ }^{3}$ ou com

1 Heinrich Mann (1871-1950), no romance Entre as raças [Zwischen den Rassen], que em breve será lançado em tradução brasileira (de Fernanda Boarin Boechat, pela editora Candela, de Curitiba) dedicase a figurar e transformar no universo da ficção, a partir do diálogo com as memórias de Julia Mann, a situação sociocultural e psíquica da mãe brasileira em seus anos de infância e adolescência em Lübeck. Sobre isso, cf. Soethe, 2006a; Kuschel/Mann/Soethe, 2009 (cap. 2). No Brasil, o romance Ana em Veneza, de João Silvério Trevisan (1994, trad. alemã: 1997), também toma a figura de Julia Mann como ponto de partida para refletir sobre situações de identidade, trânsito e "exílio" cultural. Desenvolvo [S.P.] dissertação de mestrado sobre esse romance brasileiro e sua relação com a obra de Thomas Mann, em especial a narrativa A morte em Veneza.

2 Sobre o assunto, cf. o estudo exemplar de Elsaghe (2004).

3 Há registros de contatos da família Mann, por carta, com parentes no Brasil. Em 23/12/1942, Thomas Mann registra em seu diário: "Carta em inglês para Julia Pedroso em São Paulo, prima” (Tb, p. 512). Julia Pedroso (1870-1969) era filha de Heinrich Nicolaus Stolterfoth e de sua mulher Maria, nascida da Silva Bruhns, irmã de Julia Mann. Anos mais tarde, em 09/01/1948, uma nova informação no diário de Thomas Mann sobre esse contato familiar: "Grande contentamento pela carta em inglês de Julia 
Paulino, S.; Soethe, P. - Thomas Mann e a cena intelectual no Brasil

diplomatas brasileiros ${ }^{4}$, mas sobretudo em razão da iniciativa e empenho de intelectuais brasileiros ou vinculados ao Brasil.

\section{O retrato da mãe: Julia Mann por Thomas Mann}

Thomas Mann atribui à mãe o importante papel da musicalidade em sua vida e associa tal aptidão à origem étnica de Julia Mann, sob noções vagas de uma “psicologia dos povos" bastante difundida na época. Em uma carta de junho de 1939 à mecenas americana Agnes E. Meyer, o escritor ressalta a "propensão ao 'Sul', à arte e à boemia" que havia em sua mãe:

Minha herança paterna e materna divide-se exatamente segundo o modelo goetheano: do pai a "estatura", ao menos uma dose disso, e „o jeito sisudo de ser"; da "mãezinha", tudo que G. [Goethe] resume simbolicamente nas palavras "alegria, candura" e a "vontade de

Petroso (sic), nascida Stolterfoht de Sao Paulo" (Tb, p. 209). [Como acima, nesta mesma nota, todas as citações seguintes referentes aos diários de Thomas Mann serão introduzidas apenas pelas iniciais $\mathrm{Tb}$, seguidas do número da página; a data remete ao respectivo volume na edição indicada nas referências bibliográficas, de 2003.]

Cartas inéditas de Erika Mann à "Srta. Stolterfoht" (de 2 e de 24/03/1960, disponíveis no Arquivo Literário Municipal de Munique, Monacensia, cf. Documentos) registram o encontro da filha do escritor com essa provável prima distante pela linhagem brasileira da família. Trata-se, provavelmente, de Caroline Amalia Oscara Stolterfoht, pois é a única filha de Maria que não se casou, o que justifica a referência a "Fräulein", de Erika, na carta (cf. Krüll 1997: Anexos).

4 Thomas Mann manteve contato com alguns diplomatas brasileiros. Em anotação em seu diário de 18/11/2009 ele registra, por exemplo: "Jantar com enviados brasileiros e tchecos e suas esposas". Mais importante ainda o encontro de 30/06/1940: "O enviado brasileiro. Com ele, e por causa de Golo, à mesa, mais tarde." Em 29/02/1940 Thomas Mann já havia registrado: "Sobre Golo, sua permanência problemática, a conveniência de sua vinda [...]”. Está em questão a possibilidade de um visto brasileiro para a saída de Golo Mann da Alemanha, e a ocasião logo se oferece. Segundo Schneider (2001: 83), a associação católica St. Raphael "realiza uma importante ação de salvamento dos assim chamados cristãos não-arianos [...]. Seus esforços de possibilitar a emigração de alemães para além-mar, sobretudo para o Brasil, encontra apoio do Vaticano [...]: por iniciativa do presidente da Associação St. Raphael, do bispo Wilhelm Berning, e do cardeal Michael von Faulhaber, Pio XII empenha-se junto ao governo brasileiro pela permissão de 3000 vistos para cristãos não-arianos; o presidente Vargas aceita, por fim. Deste contingente, 100 vistos foram redirecionados para emigrantes que se dirigiam a outros países da Europa, cuja partida foi se tornando cada vez mais difícil, após a eclosão da guerra. Possivelmente Golo Mann dispôs de um desses vistos. Na página 119 do catálogo da exposição "Brasil, um refúgio nos trópicos. A trajetória dos refugiados do nazi-fascismo" (Carneiro 1995), encontra-se uma cópia pouco legível de um telegrama de 2 jul. 1940, que Carlos Martino Pereira e Souza (da embaixada brasileira de Washington) envia para o Ministério de Relações Exteriores do Brasil com o pedido de permissão para fornecer um visto de entrada a Angelus Gottfried Thomas Mann (Golo Mann), filho de Thomas Mann e neto da brasileira Julia da Silva Bruhns. Nesse mesmo telegrama, o nome "Meyer" relaciona-se claramente ao de Agnes Meyer, que se empenhava pela concessão do visto. 


\title{
Paulino, S.; Soethe, P. - Thomas Mann e a cena intelectual no Brasil
}

histórias tecer", o que nela assumia formas bem diferentes, é claro. Sua natureza pré-artística e sensível expressava-se na musicalidade, em seu piano tocado com bom gosto e com a aptidão proporcionada por uma formação burguesa consistente, e em sua refinada arte de cantar, à qual devo meu bom conhecimento da canção alemã. Ela foi levada a Lübeck ainda em tenra idade, e enquanto durou lá sua lida com as obrigações da casa comportou-se como uma boa filha da cidade e de seus extratos sociais mais elevados; uma corrente interior de propensão ao "Sul", à arte e à boemia, no entanto, jamais deixaram de estar claramente presentes. (MANN 1961ss.: vol. 2: 100s.)

Mesmo em Lübeck, uma cidade marcada pela sobriedade do Norte alemão, Julia Mann mantinha em sua casa uma vida social movimentada. Segundo Katia Mann, ela era na sociedade de Lübeck "um peixe fora d'água" (“ein fremder Vogel”, cf. MANN 1976: 31). A casa era frequentada por artistas e intelectuais, a anfitriã promovia bailes e via-se cercada de oficiais, músicos e gente de teatro que lhe faziam a corte. Seu filho Thomas descreve-a em Das Bild der Mutter (O retrato da mãe), de 1930, como a seguir:

\begin{abstract}
Nossa mãe era de beleza extraordinária; sua presença, espanhola, não restava dúvida - voltei a encontrar certos traços da raça e do habitus em dançarinas famosas -; irradiava o esplendor sulino de marfim, era nobre o feitio de seu nariz, e a boca formosa como jamais vi outra.

[...] e mesmo que nós, eu e meus irmãos, enquanto crianças, estivéssemos sob a responsabilidade de uma governanta para os cuidados principais, o lar ainda conservava um caráter suficientemente burguês para que sempre houvesse contato entre nós e nossa mãe, e ela com freqüência nos dedicava suas noites livres, quando lia histórias de Fritz Reuter para nós, sob a luminária da mesa da sala. Era surpreendente como o dialeto de Mecklenburg soava bastante bem em sua boca exótica, e ela o dominava melhor que qualquer outra pessoa em casa. (MANN 1983: 153)
\end{abstract}

Em outubro de 1891, com apenas 51 anos de idade, morre o marido de Julia Mann, e assim ela se liberta da cinzenta cidade hanseática. Muda-se em junho de 1893 para a alegre capital bávara, Munique. Ali espera vivenciar mais sua inclinação para a extravagância, para a música e as artes em geral, o que de fato se concretiza em uma primeira fase. Em sua autobiografia, o músico Karl Ehrenberg, amigo da família, descreve as noites de leitura e de música na casa hospitaleira da senhora Mann, um "ponto de encontro de jovens animados e interessados pelas artes, onde vivíamos horas inesquecíveis e cuja atração e interesse eram ainda mais realçados pela amabilidade da anfitriã e de suas duas belas filhas Julia e Carla” (STRAUSS 1997: 77). 


\title{
Paulino, S.; Soethe, P. - Thomas Mann e a cena intelectual no Brasil
}

Thomas Mann não deixa de enfatizar em Das Bild der Mutter o talento musical de sua mãe, que não deixou de ter conseqüências sobre os filhos:

\begin{abstract}
Mais ainda me agradava acompanhar minha mãe quando ela se dedicava à música. Seu piano de cauda Bechstein ficava no salão, um cômodo claro com sacadas, em que o estilo burguês pomposo de 1880 tratava de abrigar com bom gosto uma paz sem vencidos nem vencedores, e ali eu ficava sentado horas e horas em uma das poltronas cinzas-claras estofadas e ouvia a música bem executada e sensualmente acurada de minha mãe, que eu percebia mais alegre nos Études e Noturnos de Chopin. (MANN 1983: 154)
\end{abstract}

Os desdobramentos dessas impressões "brasileiras" e europeias da infância do escritor, que marcaram sua autocompreensão e universo poético, foram percebidas anos depois por um importante contemporâneo seu e oferecem nesse caso uma chave de leitura curiosa para quem se aproxima do autor.

\section{Os olhos brasileiros de Thomas Mann}

Theodor W. Adorno, um dos mais influentes pensadores na Alemanha do pósguerra, esboçou em 1962, seis anos após a morte de Thomas Mann, seu retrato pessoal do "Mago" (epíteto atribuído com frequência ao escritor). A intenção despretensiosa de Adorno (1972: 7) era dizer "algumas palavras sobre a pessoa e não sobre a obra" do escritor, com quem havia convivido no exílio na Califórnia e a quem considerava um interlocutor admirável. Filósofo e musicólogo proeminente, Adorno integra a seu "retrato" de Mann uma menção peculiar ao Brasil.

Seu objetivo, no ensaio publicado em uma coletânea por ocasião dos 85 anos de Hermann Hesse, não seria apresentar lembranças pessoais de Mann, mas, segundo Adorno, "a partir da minha própria experiência, (...) refutar alguns preconceitos que teimosamente pesam sobre a pessoa do escritor" (1972: 7). Estes preconceitos "não são indiferentes ante a composição da obra, sobre a qual quase se transportam de modo automático: eles a obscurecem à medida que ajudam a reduzi-la a fórmulas" (idem). O filósofo, em face da fórmula bastante disseminada do "conflito entre o burguês e o artista, herança da antítese nietzscheana entre a vida e espírito" (idem), 
Paulino, S.; Soethe, P. - Thomas Mann e a cena intelectual no Brasil

pretende combater a caracterização apressada de Thomas Mann como artista burguês avesso à vida e suas dinâmicas sociais.

Adorno destaca a complexidade e multiplicidade da pessoa e da obra de Mann, pois "apesar de toda a força de seu Eu, não era sua identidade quem ditava a última palavra" (1972: 11). Salienta, no comportamento do retratado, justamente seu distanciamento e recolhimento nos momentos de partilha social: "É bem possível que, durante eventos sociais, que de modo algum costumavam aborrecê-lo, o espírito pesado o conduzisse às esferas do sono acordado" (1972: 11). Mas Adorno não via nisso qualquer ausência de sensibilidade por parte do escritor. Para ele, pelo contrário, era esse o momento em que "ele se preparava para arrancar a máscara" (1972: 11), quer dizer, a máscara do "filho do senador de Lübeck, frio e reservado" (1972: 9). Então segue, em posição de destaque no texto de Adorno, uma alusão à origem brasileira de Thomas Mann:

Se eu tivesse que dizer o que nele me parecia o mais característico, deveria mencionar o gesto de repentino sobressalto que se podia aguardar nessas ocasiões. Seus olhos eram azuis ou azuis cinzentos, porém naqueles momentos em que ele encontrava a si mesmo, fulguravam negros e brasileiros, como se algo ardesse estagnadamente e esperasse seu momento de inflamação; como se se tivesse reunido algo material de que agora ele se apoderava para experimentar suas forças. $\mathrm{O}$ ritmo do seu sentimento de vida era o contrário do burguês; nada de continuidade, mas antes a alternância entre extremos, entre estagnação e iluminação. Este fato talvez irritasse amigos da mornez, do aconchego antigo ou novo. Pois nesse ritmo no qual um estado negava o outro, veio à luz a ambigüidade do seu natural. (ADORNO 1972:11)

Os olhos, "negros e brasileiros"? O retrato de Adorno não decifra o mistério de Mann enquanto "filho do senador de Lübeck", mas quer intensificá-lo pela remissão à origem sul-americana de sua pessoa. Essa ambivalência de Mann, identificada com sensibilidade pelo filósofo, também se espelha na relação reflexiva do escritor com sua origem. Indiferença, distanciamento e mesmo negação, em especial no início da vida pública, irão alternar-se com declarações de valorização desse componente de diversidade étnica e cultural em sua pessoa e com manifestações de interesse pelo país exótico em que havia nascido e crescido sua mãe. 
Paulino, S.; Soethe, P. - Thomas Mann e a cena intelectual no Brasil

\section{4. $\bigcirc$ Brasil nos livros}

Algumas poucas leituras serviram a Thomas Mann como fonte de informação sobre o Brasil. Elas se limitam a Brazilian Adventures, de Peter Fleming (1907-1971), conforme registro no diário do escritor em 26/09/1935: "Leio com prazer o livro de viagens sobre o Brasil do jornalista inglês Fleming. - Vou tarde para cama.” (Tb, p. 179) Na obra, Fleming conta suas aventuras: atraído por um anúncio no The Times, participou de uma expedição que percorreu os rios Araguaia e Tapirapé, organizada por instituições inglesas que pretendiam encontrar o Coronel Percy Harrison Fawcett (1867-1925?), explorador inglês desaparecido no Mato Grosso em meados dos anos 1920.

Outro título é Brasilien, ein Land der Zukunft (1941) [Brasil, país do futuro], de Stefan Zweig. Comprova-o o registro de 4/12/1941 no diário (Tb, p. 356): “Após o jantar o livro de Stefan Zweig sobre o Brasil." Cabe aqui caracterizar rapidamente a relação delicada de Thomas Mann em face do escritor austríaco. Stefan Zweig, depois de percorrer diversas estações em seu itinerário de fuga do nazismo, como exilado, fixa-se na cidade de Petrópolis. Lá, em fevereiro de 1942, comete suicídio justamente no "país do futuro" que pouco antes havia constituído objeto de louvor em sua própria obra: em um tempo de guerra e tantos ódios raciais, Zweig argumenta que o Brasil merece grande admiração internacional, por abrigar culturas e etnias múltiplas de maneira pacífica e integradora.

Em uma carta à primeira esposa de Stefan Zweig, Friderike Zweig, Thomas Mann se posiciona sobre o aparente descaso e frieza que ele mesmo teria expressado publicamente, em texto que escreve pouco após a morte do escritor. Mann argumenta, em favor de si mesmo, não ser uma tarefa difícil homenagear escritor de tamanha estatura, mas, ao mesmo tempo, não poder calar sobre o caráter condenável da saída que Zweig encontrara para seu desespero: o suicídio.

Mann entende que para uma personalidade de "tendência radicalmente pacifista", não havia, em tempo de guerra, mais que "infelicidade sangrenta". Zweig não teria conseguido suportar viver em um país em que se concebesse a guerra, e quando até mesmo o Brasil mostrou-se inclinado a tomar parte dela, Zweig não logrou mais suportar essa situação. Para Mann, no entanto, a decisão extrema de Zweig 
Paulino, S.; Soethe, P. - Thomas Mann e a cena intelectual no Brasil

configura-se como um ato de fraqueza e de "renúncia", e não poderia ter qualquer consequiência prática exceto o "silêncio". Era como se Stefan Zweig tivesse desconsiderado os "milhares para quem seu nome era importante" e os que não tiveram sua mesma sorte.

A carta de Thomas Mann a Friderike Zweig termina, de qualquer modo, com uma pequena celebração do escritor austríaco, e Mann reforça que sua dor seria tão grande quanto a dos que a expressaram massivamente em publicações honrosas. Tampouco as homenagens provindas do Brasil escaparam aos olhos do escritor, que com "verdadeira satisfação" as teria lido e igualmente se alegrado com "as honrarias públicas que eram prestadas ao falecido pelo país de seu último exílio" (MANN, 1961ss.: vol. 2: 281s.).

O contexto sociopolítico brasileiro virá se tornar mais claro para Thomas Mann alguns meses mais tarde, por meio de sua leitura do estudo histórico e sociopolítico Brazil under Vargas, de Karl Loewenstein (1891-1973). A propósito, Loewenstein, importante pensador alemão, considerado um dos pais do constitucionalismo moderno, dedicou sua obra a Mann, como se lê já na primeira edição, de 1942: „To Thomas Mann, in token of many years of friendship“ (p. V). O início da leitura do livro e a constatação da dedicatória são mencionadas no diário em 25/09/1942. Dali a dois dias, novo registro: "Li 'Brazil under Vargas' de Loewenstein" (Tb, p. 478). Em 29/09/1942 (Tb, p. 479), menciona-se uma carta enviada ao "Prof. Loewenstein", em agradecimento pela obra.

Outra obra sobre o Brasil recebida por Mann é Estrangeiro. Der Fremdling, de Heinrich Eduard Jacob (1889-1967). A observação no diário de Mann (21/5/1951) é a seguinte: “"Estrangeiro', romance de H. E. Jacob, algo brasileiro.“ (Tb, p. 122) Entusiasmado com a obra, Thomas Mann escreve uma carta ao escritor em 24/10/1951, em que considera o romance envolvente e emocionante. Ele o teria lido em curto espaço de tempo e apreciado a descrição da natureza (Cf. MANN 1976-1987 51/428: 88)

Por fim, uma última obra que cabe mencionar aqui foi organizada e publicada apenas recentemente pelo professor Reinhard Andress, da University of St. Louis, nos Estados Unidos. Em seu posfácio ao romance Der Schmelztiegel, de Marte Brill, Andress menciona haver no espólio dessa escritora a cópia de uma carta de Thomas 
Paulino, S.; Soethe, P. - Thomas Mann e a cena intelectual no Brasil

Mann, de 08/07/1941. Na carta, Mann mencionaria um manuscrito que Brill teria enviado a ele e no qual ele haveria elogiado sua "tenacidade e pertinácia artística", bem como seu "talento". Mann encontraria no manuscrito "algo tocante e instigante sobre a tragédia desta época" (BRILL 2002: 346). Na correspondência trata-se justamente do romance Der Schmelztiegel, em que a escritora narra sua vinda ao exílio no Brasil, com a filha, por conta da perseguição aos judeus na Alemanha durante a Segunda Guerra Mundial.

Ainda segundo Andress, no posfácio de Der Schmelztiegel Thomas Mann teria aconselhado Marte Brill a enviar a tradução em língua inglesa do romance, feita por Ruth Mary Moore, diretora da São Paulo Graded School, para a editora Knopf, de Nova York. A editora não mostrou interesse pela obra, assim como havia ocorrido com uma versão em português, que se havia pretendido publicar, sem êxito, pela editora Brasiliense. Sob o governo de Getúlio Vargas, o país que havia dado asilo a essa vítima do fascismo alemão também teria censurado a publicação por razões políticas.

Para além dos contatos livrescos com o Brasil, Mann teve também encontros pessoais com intelectuais brasileiros como Sérgio Buarque de Holanda e Erico Verissimo. Esses encontros impactam os brasileiros, mas não guardam registro por parte de Thomas Mann. Gilberto Freyre, por sua vez, é mencionado por Mann em carta, mas um encontro entre ambos, que poderia ter sido possível durante uma eventual viagem do escritor alemão ao Brasil, jamais acontece. Assim, o contato efetivo, registrado em correspondência e diário, e mesmo significativo para a caracterização do escritor e de sua obra, restringe-se ao diálogo com dois exilados no Brasil: Herbert Caro e, mais extensamente, Karl Lustig-Prean.

\section{Um encontro em Berlim: Sérgio Buarque de Holanda}

O encontro entre Sérgio Buarque de Holanda e Thomas Mann ocorreu em 18 de dezembro de 1929, em Berlim. Sobre ele há um relato do próprio Sérgio Buarque reeditado no primeiro volume de $O$ espírito e a letra. "Acho impossível dispensar o prazer de conversar com um brasileiro", teria afirmado Thomas Mann na época, 
Paulino, S.; Soethe, P. - Thomas Mann e a cena intelectual no Brasil

explicando a Sérgio Buarque por que ele, e não outro, havia sido escolhido para falar com o laureado com o prêmio Nobel, em meio a tantas outras solicitações de entrevistas.

Sérgio Buarque confessa em seu registro do encontro haver considerado até então apenas uma lenda a origem brasileira de Mann, sobre a qual teria tido informação através de um certo Adolf Bartels, o qual se esforçava no entanto para desqualificar essa origem "vergonhosa" de Mann, segundo relata Sérgio Buarque. Na conversa com ele, Mann teria oferecido ao brasileiro informações sobre sua origem e lhe apresentado o argumento de uma gênese poética marcada pelo "sangue brasileiro herdado de minha mãe". E Thomas Mann acrescenta, segundo o relato de Sérgio Buarque: "Penso que nunca será demais acentuar essa influência quando se critique a minha obra ou a de meu irmão Heinrich" (HolANDA 1998: 255).

Ora, Sérgio Buarque indicou como fonte de seu conhecimento da origem brasileira de Mann a leitura do historiador literário Adolf Bartels. Se esse historiador, segundo informação de Buarque de Holanda, tratava de pôr em questão a origem brasileira de Thomas Mann "como se fosse qualquer coisa de lamentável e de quase vergonhoso" (para indignação de HolANDA 1998: 263), o fato é que o próprio Mann, anos antes, em 1912 e 1913, havia mantido polêmica com o crítico alemão, que insistia em ver no autor de Os Buddenbrook traços judeus, tanto culturais quanto raciais.

Sem eximir-se do peso da mentalidade da época, Thomas Mann trata de replicar o anti-semita Bartels, negando obstinadamente uma eventual origem judaica: “como não sou judeu - e isso em nenhuma gota sequer de meu sangue - não posso desejar que alguém me tome por judeu” (Thomas MANN apud KURZKE 2000: 212). A pretensa "acusação" de Bartels contra Thomas Mann, segundo a lógica perversa e insana do antissemita, remonta à origem portuguesa de Julia Mann, “já que o povo português é o pior de todos os povos europeus, do ponto de vista racial: basta ver a Enciclopédia Meyer para Conversação, que destaca a mistura de árabes, judeus, indianos e negros."

O incansável Bartels insiste ao longo de décadas em versar sobre Heinrich e Thomas Mann, e ainda em 1942, na $18^{\mathrm{a}}$ edição de sua História da literatura alemã, ainda se lê que a mãe de ambos era portuguesa e que "portanto possivelmente não 
Paulino, S.; Soethe, P. - Thomas Mann e a cena intelectual no Brasil

estava livre de sangue judeu e negro; e não vá se esquecer que ambos se casaram com judias”. Infelizmente, tal raciocínio era corrente nas primeiras décadas do século XX, e não apenas na Alemanha. Entre nós, a obra do historiador antissemita brasileiro Gustavo Barroso, História secreta do Brasil, é sinal tão evidente quanto deplorável da relevância desse tema, que talvez também viesse à baila nas conversas cotidianas mantidas entre Julia Mann e seus filhos.

Um exemplo de alusão ao Brasil na obra de Thomas Mann, e que parece fazer referência a uma das razões que enfraquece o empenho do escritor por afirmar sua origem brasileira, é a menção de brasileiros em A montanha mágica. Embora discreta, ela alude, no âmbito da ficção, a uma questão ligada a controvérsias ao longo da vida política de Thomas Mann. Ao informar o leitor sobre a vida de Leo Naphta, este jesuíta de origem judaica, favorável ao terror e defensor convicto de uma teocracia comunista, uma das figuras magistrais com que o protagonista Hans Castorp tem contato em A montanha Mágica, o narrador apresenta no romance o seguinte comentário: "O cosmopolitismo da instituição [o seminário jesuíta] impedia que sua origem racial [judaica] aparecesse de modo evidente. Existiam ali jovens provenientes de terras longínquas, sul-americanos de raça lusa, cujo aspecto era mais 'judeu' que o de Leo, e dessa forma o conceito deixou de subir à tona" (MANN 2000: 607).

A frase seguinte no romance menciona de forma aparentemente gratuita a presença de um príncipe etíope, "um tipo negro de carapinha, muito nobre, no entanto" (MANN 1996: 622), que ingressava no seminário à mesma época que Nafta. Ora, a única e breve alusão a brasileiros em todo o romance destaca uma suposta semelhança entre judeus e brasileiros e faz menção fortuita ao africano.

Parece significativo que também em outro romance de Thomas Mann, As confissões do impostor Felix Krull, ocorra nova associação entre brasileiros e judeus. O protagonista Felix, em Frankfurt, depara com um casal de irmãos e por sua beleza percebe neles "uma aparência de além-mar, de cabelos escuros, talvez argentinos, brasileiros - tento adivinhar; mas quem sabe sejam judeus também" (FA: 88s.).

A questão, que aparece cifrada nos dois romances, mas já havia sido motivo de breve polêmica no espaço público alemão entre Mann e Bartels, perde força quando o domínio nazista e as práticas antissemitas vão exigindo mais e mais uma posição clara de Thomas Mann, que afinal não hesita em assumi-la e em se tornar um dos 


\section{Paulino, S.; Soethe, P. - Thomas Mann e a cena intelectual no Brasil}

opositores mais ferrenhos do nazismo, após o início da Guerra. É nessa fase que ocorrerá o encontro entre ele e Erico Verissimo.

\section{Denver, 1941: Erico Verissimo}

Thomas Mann teria tido um breve encontro ainda com outro intelectual brasileiro de grande renome, Erico Verissimo. No dia 10 de agosto de 1939, havia sido anunciada no Correio do Povo uma viagem de quatro meses do escritor brasileiro, cuja partida estava prevista para dali a quinze dias, em 25 de agosto. Professores da Universidade de Michigan haviam-no convidado para proferir palestras.

Também a União Pan-Americana de Washington havia feito um convite a membros do Instituto Cultural Brasileiro Norte-Americano para uma visita ao país. Verissimo estava entre os convidados. O escritor brasileiro tinha várias perspectivas para a viagem, sobretudo a realização de reportagens e artigos que pudessem resultar de uma série de entrevistas a "homens de alto valor que foram da Europa, fugindo a odiosas perseguições políticas e raciais” (TORRESINI 2003: 299). Verissimo ressalta: "Procurarei também esses grandes exilados entre os quais se contam algumas das melhores cabeças pensantes da humanidade de hoje" (2003: 299).

Novamente no Correio do Povo, em 22 de maio de 1941, anunciam-se o regresso do escritor e uma entrevista em que este pontua alguns acontecimentos. Entre as vinte e quatro conferências proferidas e o anúncio da tradução de Caminhos cruzados, o escritor afirma ter tomado "cerveja, burguesamente, em Denver, com Thomas Mann" (2003: 312).

O encontro de Erico Verissimo com Thomas Mann marcou profundamente o escritor brasileiro. Como diretor da seção de literatura da editora Livraria do Globo, Verissimo, ainda antes do encontro de 15/03/1941 em Denver, já tinha organizado a publicação da tradução de Os Buddenbrooks e A montanha mágica por Herbert Caro. Em seu livro de viagens Gato Preto em Campo de Neve, o escritor gaúcho apresenta uma impressão detalhada e bastante positiva da pessoa de Thomas Mann, bem como o conteúdo da conversa entre ambos. 
Paulino, S.; Soethe, P. - Thomas Mann e a cena intelectual no Brasil

No início do capítulo “Thomas Mann”, em que o episódio é narrado, menciona-se um outro provável encontro que ambos teriam tido em Princeton. Bastante surpreso pela presença de Mann na cidade de Denver, o escritor gaúcho não perde o ensejo de comentar a origem de seu colega alemão:

- Diga-me, Herr Mann - pergunto - é verdade que um de seus antepassados nasceu no Brasil?

- Sim. Minha mãe nasceu no seu país. Era filha de pai alemão e de mãe brasileira.

- Mas... brasileira só de nascimento ou também de sangue?

- Minha vó materna tinha sangue português e índio. (VERISSIMO 1961: 253)

Em seguida, Verissimo descreve a impressão que teve de Mann:

É um homem de estatura pouco abaixo da mediana. Tem o rosto comprido e estreito, a testa alta, de cenho quase sempre cerrado, um nariz comprido, bigode aparado e ralo, cabelos escuros levemente grisalhos. Suas faces são dum vermelho lustroso, o que lhe dá um agradável aspecto de saúde. Sua voz é grave e meio áspera, e seu todo é o de um simples e tranqüilo professor. (idem)

O brasileiro afirma ainda que Thomas Mann era uma "criatura [...] bastante diferente do retrato que dela me pintaram alguns escritores que o conhecem: um magister grave, dogmático e de ar suficiente, desses que levantam o indicador e dizem sempre a palavra definitiva sobre todos os assuntos" (1961: 254).

O próprio Thomas Mann infelizmente não menciona o encontro com o escritor brasileiro, tanto menos seu nome. Há nos diários de Mann, no entanto, uma menção objetiva sobre o programa de que ele teria se incumbido naquele dia, em Denver, e que ao menos coincide com o que descrevera Erico Verissimo.

Em carta a Thomas Mann de 14/10/1941, o tradutor Herbert Caro transmite, com muita admiração, saudações de Verissimo, "diretor de nossa editora, que o Sr. conheceu em Denver" (Kuschel/ManN/SOETHE 2009: 202). Esta carta, cuja cópia está disponível no Arquivo Herbert Caro, Thomas Mann não chegou a receber, pois ela se extraviou. Recebeu, sim, somente outra versão de mesmo teor, enviada em 15/04/1942, mas que não se encontra no arquivo. Na resposta de Thomas Mann de 
Paulino, S.; Soethe, P. - Thomas Mann e a cena intelectual no Brasil

05/05/1942 não há qualquer menção às lembranças mandadas por Erico Verissimo, ou porque nessa carta de maio Herbert Caro não menciona mais as lembranças, ou porque, caso o tenha feito, Mann simplesmente desconsidera a saudação, ou ela lhe passa despercebida.

\section{Exilado e militante: Karl Lustig-Prean}

Pouco tempo após esse encontro com Erico Verissimo, e trinta anos depois da polêmica pública entre Thomas Mann e Adolf Bartels sobre a origem étnica do escritor, outro acontecimento acaba por intensificar a relação de Thomas Mann com a cena brasileira.

Desde meados de 1937, vivia exilado em São Paulo o dramaturgo austríaco Karl Lustig-Prean (1892-1967) ${ }^{5}$. Intelectual progressista católico, ele assumiu desde cedo no Brasil a função de líder do Movimento dos Alemães Livres, uma coalisão de militantes alemães anti-hitleristas articulada em nível internacional (sobre o assunto, cf. HAMACHER: 2005). Inicialmente ligado ao movimento A Outra Alemanha, presente na Argentina e de orientação social-democrata, a ala brasileira do movimento irá se filiar em 1943 ao Comitê Latino-Americano dos Alemães Livres, liderado pelo comunista Ludwig Renn (1889-1979) e apoiado por escritores famosos como Anna Seghers e Heinrich Mann, na condição de seus presidentes de honra. Também Thomas Mann manifesta apoio à iniciativa em carta de 10/04/1942. Em seu diário, na anotação de 18/8/1943, ele relata, inclusive, haver recebido a visita de "dois cavalheiros do F.B.I. em razão do grupo no México". O anticomunismo norteamericano irá se intensificar e será fator decisivo para a decisão de Mann de deixar o país nos anos 1950 e retornar à Europa.

\footnotetext{
5 Registro aqui meus agradecimentos a Izabela Maria Furtado Kestler (1959-2009). Em uma conversa pessoal em 2000, a colega despertou-me [P.S.] a atenção para a presença de Lustig-Prean no Brasil e para a correspondência dele com Thomas Mann. Izabela falou-me naquela ocasião de sua tese de doutoramento (Kestler 1992), que os leitores brasileiros tiveram a felicidade de ver traduzida recentemente (Kestler, 2004). Da mesma forma, agradeço o jornalista e cineasta Marcos Strecker e Simone Malaguti, que me forneceram primeiras cópias de algumas das cartas trocadas entre Mann e Lustig-Prean e me indicaram a existência do Arquivo Lustig-Prean na Biblioteca Nacional Austríaca, em Viena, onde a pesquisa pôde ter continuidade.
} 


\section{Paulino, S.; Soethe, P. - Thomas Mann e a cena intelectual no Brasil}

Sob a ditadura Vargas, tais atividades políticas, sobretudo quando exercidas por um estrangeiro de língua alemã, não se desenvolviam sem imensas dificuldades. Por um lado, havia no governo brasileiro forte presença de simpatizantes tácitos do nazismo no Brasil; por outro lado, cumpria-se uma política severa de nacionalização que havia proibido o uso do idioma alemão. É somente com a inversão das perspectivas na guerra, o enfraquecimento militar da Alemanha a partir de 1941 e a progressiva aproximação do Brasil aos Estados Unidos que a situação se torna menos desfavorável junto às autoridades brasileiras. Em 4 de setembro de 1942, Lustig-Prean escreve sua primeira carta a Thomas Mann, ${ }^{6}$ na qual lhe comunica a oficialização do Movimento dos Alemães Livres do Brasil em "maio do corrente ano", sob a "tolerância das autoridades" brasileiras e "após anos de difícil existência" do grupo cultural que lhe deu origem.

O envio da carta é justificado pelo desejo de informar Thomas Mann dos acontecimentos e por ser ele "o centro intelectual e espiritual de todos os movimentos livres alemães". Não havia exagero: essa posição central era reconhecida em nível internacional, particularmente pela atuação e discursos contundentes do escritor contra o nazismo, redigidos e difundidos no exílio norteamericano, no rádio e na imprensa internacionais. Mann responde a carta de maneira breve, mas prontamente (já em 30 de setembro) e com palavras calorosas de agradecimento pelas informações “interessantes e aprazíveis".

Em 8 de abril de 1943, segue nova correspondência de Mann a Lustig-Prean. A carta é bem mais longa (uma lauda completa) e de iniciativa própria, talvez ocasionada pela passagem dos vinte anos de morte da própria mãe, Julia, falecida em 11 de março de 1923. Pois ainda que a correspondência manifeste a intenção de agradecer a atuação dos integrantes do Movimento dos Alemães Livres do Brasil e cumprimentá-los pelo primeiro ano de existência de sua agremiação "sob o reconhecimento das mais altas autoridades do país", o tom do texto revela-se na verdade bastante pessoal. Na carta, lê-se a declaração mais contundente de Thomas Mann sobre a importância da própria origem brasileira em sua formação como pessoa e artista. Seu agradecimento não vai apenas às pessoas ligadas ao Movimento:

9 Cartas trocadas entre Thomas Mann e Karl Lustig-Prean cf. Kuschel/ Mann/ Soethe (2009: 220-237).

Pandaemonium germanicum 14/2009.2, p. 28-53 - www.fflch.usp.br/dlm/alemao/pandaemoniumgermanicum 
Paulino, S.; Soethe, P. - Thomas Mann e a cena intelectual no Brasil

Dirige-se também ao país imenso e acolhedor que lhes oferece proteção e liberdade de atuação e ao qual me sinto ligado por laços sangüíneos. Cedo soou em meus ouvidos o louvor de sua beleza, pois minha mãe veio de lá, era uma filha da terra brasileira; e o que ela me contou sobre essa terra e sua gente foram as primeiras coisas que ouvi sobre o mundo estrangeiro. Também sempre estive consciente do sangue latinoamericano que pulsa em minhas veias e bem sinto o quanto lhe devo como artista. Apenas uma certa corpulência desajeitada e conservadora de minha vida explica que eu ainda não tenha visitado o Brasil. A perda de minha pátria [mein Vaterland] deveria constituir uma razão a mais para que eu conhecesse o país de minha mãe [mein Mutterland]. Ainda chegará essa hora, espero (MANN, Briefe, vol II, 1963: 306).

O apoio ao movimento político antinazista no Brasil e a manifestação sentimental sobre a origem familiar mesclam-se na carta de Thomas Mann. Soa nela um aspecto interessante de sua produção: a atenção a elementos estrangeiros (estranhos, alheios) ${ }^{7}$. O jogo com as palavras "Vaterland" e "Mutterland" e a menção das primeiras experiências com o mundo estrangeiro fazem pensar no momento particularmente interessante vivido por Mann em seu percurso intelectual e de atuação política. Estava cumprido o abandono de qualquer chauvinismo, com a consciência da responsabilidade coletiva do povo alemão pelo advento do nazismo, e era sincero o apoio à atuação política como atividade legítima e valorosa, sinal claro da superação de idealizações e arrogância do "apolítico" de $1918 .{ }^{8}$

A correspondência com Lustig-Prean prossegue com mais uma carta de Mann de agosto de 1943, de agradecimento por material enviado, e outra em 11 de dezembro de 1944, em resposta a uma sinopse que o dramaturgo austríaco lhe envia em alemão, de um artigo seu intitulado "Escritores alemães no exílio", publicado no Boletim Biblio-Graphico da Biblioteca Municipal de São Paulo (vol. 3, 1944), com uma seção dedicada à família Mann.

7 Em alemão, as noções de estrangeiro, alheio e estranho convivem sob o termo "fremd" (como adjetivo) e em suas realizações substantivadas (ambivalentes, com freqüência): "das Fremde" é o conceito psicológico ou sociocultural que reúne os elementos de estranheza e a percepção do que é alheio; "der Fremde" (fem.: "die Fremde", pl.: "die Fremden”) designa a pessoa estrangeira, podendo significar também apenas "turista", em alguns substantivos compostos; e "die Fremde" designa a localidade estrangeira, o exterior.

8 Sobre o percurso político de Thomas Mann, cf. Soethe 2006b. 
Paulino, S.; Soethe, P. - Thomas Mann e a cena intelectual no Brasil

Essa última carta de Mann é breve, mas atenciosa e pessoal. Ele anuncia que contará a Heinrich, seu irmão, e ao filho Klaus sobre o artigo publicado em São Paulo. E ainda acrescenta, em uma referência muito elogiosa a Klaus, que este último, ora na Itália em missão militar a serviço do Intelligence Service, acabara de ler o último volume de sua tetralogia José e seus irmãos e se manifestara sobre a obra "com a inteligência crítica que admiro nele desde sempre".

Após o fim da guerra, ainda há uma troca de cartas no final de 1947, sobre o apelo que Gilberto Freyre faz à Academia Brasileira de Letras para convidar Thomas Mann a uma visita ao Brasil. A carta de Lustig-Prean, de outubro, encerra uma manifestação de apoio a Thomas Mann na polêmica que se dá entre ele e escritores alemães que haviam permanecido "em exílio interior" no país sob Hitler. Na carta, Lustig-Prean ainda manifesta sua preocupação quanto ao futuro político do Brasil.

Em maio de 1948 ocorre a última troca de cartas. Lustig-Prean pede ajuda a Thomas Mann no sentido de possibilitar seu retorno à Europa com uma recomendação junto às autoridades norte-americanas. Mann responde-lhe pronto, mas lamenta não poder ajudá-lo. Afirma não ter mais prestígio algum junto às autoridades daquele país - vivia-se o macarthismo - e lamenta não estar mais na América de Roosevelt, quando, então sim, poderia ter ajudado o parceiro de correspondência.

Por outros caminhos, Lustig-Prean logra voltar à Europa, para Viena, onde vive os últimos anos de relativo sucesso como diretor do Conservatório de Música da capital austríaca. De Viena Lustig-Prean ainda se corresponde com Katia e Thomas Mann, segundo comprovam um cartão postal enviado a ele por Mann em 11/08/1951 e uma carta enviada por Katia Mann em 7/3/1955, ambos em resposta a contatos de Karl Lustig-Prean.

\section{Esforços de Freyre e a visita que não houve}

Na carta de 31 de outubro de 1947, mencionada há pouco, Lustig-Prean havia retomado o contato com Thomas Mann "depois de um longo silêncio de ambos os lados". Nela, informa que "um dos maiores escritores e certamente o sociólogo mais representativo da América Latina, Prof. Dr. Gilberto Freyre” havia publicado um 
Paulino, S.; Soethe, P. - Thomas Mann e a cena intelectual no Brasil

artigo no Diário de Notícias (Rio de Janeiro), em 26 de outubro, intitulado "Thomas Mann, filho de brasileira”. Para a redação do presente artigo, resgatou-se o texto de Freyre no Arquivo da Biblioteca Nacional (fig.1), que segue abaixo na íntegra, na seção de Documentos.

Em seu artigo, Freyre exorta a Academia Brasileira de Letras a convidar Thomas Mann para vir ao Brasil, designado como "a maior personalidade da literatura alemã moderna". Thomas Mann se alegra com tal apelo, que o "divertira e tocara", segundo escreve em 6 de dezembro de 1947, em resposta a Lustig-Prean, para prosseguir com ponderações práticas: "Quase não consigo imaginar de que maneira a Academia Brasileira pudesse atender à sua conclamação. Ela deveria nomear-me membro-correspondente? Claro que isso seria uma honra e uma alegria para mim."

Segundo a carta seguinte de Lustig-Prean, de 1\%/05/1948, enviada a Thomas Mann antes que o austríaco deixasse o Brasil, Gilberto Freyre tomou conhecimento da carta de Thomas Mann. Ali Lustig-Prean anuncia que "um de nossos jornais, Folha da Manhã, voltou a se referir ao assunto no último domingo e exigiu uma atitude da Academia Brasileira de Letras, no sentido de honrar o maior 'filho de uma brasileira', o que seria muito natural." Esse artigo, cujo original também se encontra na Biblioteca Nacional, segue abaixo na íntegra, na seção de Documentos. 
Paulino, S.; Soethe, P. - Thomas Mann e a cena intelectual no Brasil

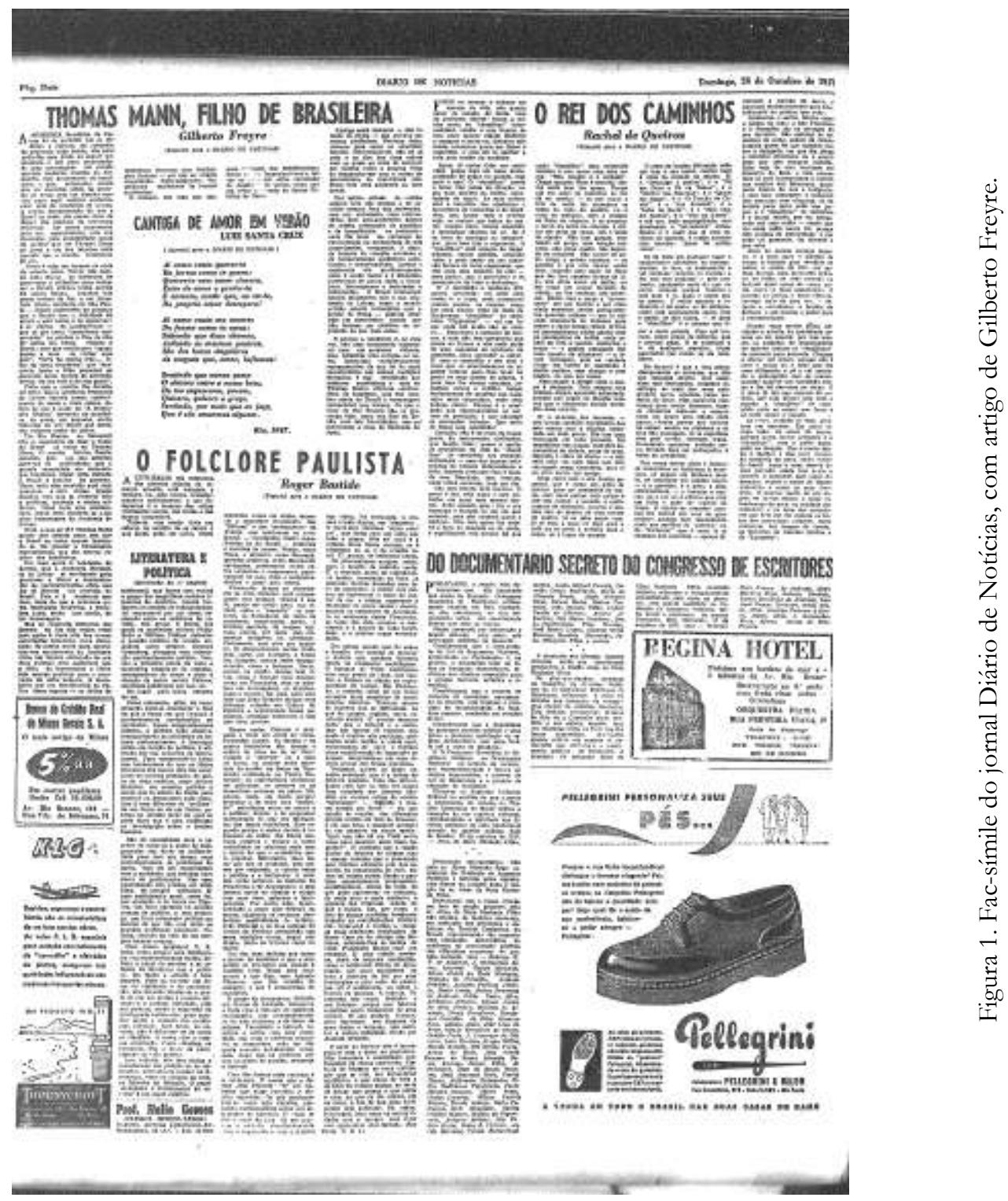

A despeito de nenhum dos anseios de Gilberto Freyre haver se concretizado na ocasião, esse último contato entre Thomas Mann e o Brasil conserva a força simbólica do encontro entre dois grandes intelectuais, mediado pela presença de um terceiro, para quem a mediação em si mesma constitui o sentido da própria atuação e atividade intelectual. Um ícone para o papel e potencialidade da germanística brasileira. Karl Lustig-Prean, nas memórias de tom cômico que publica em 1952, destaca no capítulo "Balanço e palavra final”, como principal contribuição cultural sua ao longo dos onze anos em que permaneceu no Brasil, justamente essa mediação: 
Paulino, S.; Soethe, P. - Thomas Mann e a cena intelectual no Brasil

Quando Gilberto Freyre escreveu sobre Thomas Mann, concedeu lugar central às seguintes palavras: "Leio num artigo do jornalista austríaco Carlos Lustig-Prean que Thomas Mann ainda teria a intenção de visitar o Brasil, por ser ele mesmo filho de uma brasileira. Lustig-Prean é figura esplêndida de europeu que o Brasil teve a felicidade de atrair e está tendo a de conservar". (LUSTIG-PREAN 1952: 329)

Lustig-Prean deixa o Brasil para retornar à Europa, Thomas Mann não se decide a empreender viagem ao Brasil, a Academia não reage ao apelo de Gilberto Freyre. Não obstante, o diálogo iniciado prossegue na atividade acadêmica e reflexiva da germanística (brasileira e internacional) e ainda constitui matéria fértil para pesquisa e publicações na área.

\section{Documentos}

\subsection{Cartas inéditas de Erika Mann à Srta. Stolterfoht}

2.März 1960

Sehr verehrtes Fräulein Stolterfoht, -

von Adelina Meiners höre ich, Herr Richard Marty habe mit Ihnen gesprochen und mitgeteilt, dass ich demnächst nach Lübeck komme. Sie bei dieser Gelegenheit zu besuchen, wäre mir eine besondere Freude und nicht zuletzt deshalb besonders interessant, weil Sie zu meines Vaters Tanzstundenpartnerinnen gehörten.

Ich treffe nicht, wie ursprünglich geplant, am 14.März in Lübeck ein, sondern erst am 15. Um 4 Uhr bin ich bei Fräulein Meiners, mit der es allerlei zu erörtern gibt, und hoffe, dass es Ihnen recht wäre, wenn ich anschliessend - so gegen $6 \mathrm{Uhr}$ - bei Ihnen vorspräche. Einer Antwort bedarf es nicht. Sollte Ihnen mein Besuch zur vorgeschlagenen Zeit nicht passen, so erfahre ich dies gewiss bei Fräulein Meiners.

Ich bin, mit den freundlichsten Grüssen und Wünschen,

Ihre sehr ergebene: 
Paulino, S.; Soethe, P. - Thomas Mann e a cena intelectual no Brasil

24. März 1960

Sehr verehrtes, liebes Fräulein Stolterfoht, -

Ich möchte mich doch auch auf diesem Wege nochmals bedanken für die grosse Freundlichkeit, mit der Sie mich empfangen haben. Ihre Erzählungen über das Haus in der Bäckergrube, den grässlich grossen Saal, den anschliessenden kleinen Salon mit den Wächterinnen des guten Tones und den Senator, der Sie, als noch sehr junge Mädchen, auf der Strasse zuerst grüsste, - all dies und anderes mehr habe ich mir genau und zweifellos zu meinem Nutzen im Gedächtnis aufbewahrt.

Seien Sie aufs schönste gegrüsst und nehmen Sie die besten Wünsche

Ihre sehr ergebene:

\title{
9.2. Gilberto Freyre exorta a vinda de Thomas Mann ao Brasil
}

\section{Thomas Mann, filho de brasileira9}

\section{Gilberto Freyre}

\begin{abstract}
A Academia Brasileira de Letras há de permitir que eu lhe dirija a palavra, do suburbio de provincia onde resido, não para pedir-lhe uma graça ou sequer um obsequio e sim para recomendar às suas homenagens um grande escritor moderno nascido na Alemanha, mas descendente de brasileiro; e que, entretanto, parece não ter merecido ainda do governo do nosso país um simples convite para aqui realizar conferencias; nem da Academia de Letras, a solene demonstração de que o Brasil se sente um pouco dono da figura tão gloriosa da literatura moderna; um pouco responsável pelo seu enriquecimento, pela sua formação, pela sensibilidade quase de mulher que em Thomas Mann se junta a um dos talentos mais varonis que o mundo intelectual já viu.

Mann é hoje um homem de mais de setenta anos. Talvez não queira mais dar-se ao incômodo de atravessar o Atlântico para conhecer o Brasil, embora tenha escrito há pouco tempo, segundo leio numa revista do Rio, a um jornalista tcheco residente em São Paulo - figura esplêndida de europeu
\end{abstract}


Paulino, S.; Soethe, P. - Thomas Mann e a cena intelectual no Brasil

que o Brasil teve a felicidade de atrair e está tendo a de conservar: o sr. Carlos de Lustig-Prean - que só por certo "comodismo conservador" se explica o fato de não ter ainda ele, Mann, visitado o Brasil; mas que continuava "aguardando a hora de visitar esse país", "da terra de minha mãe...filha da terra brasileira" que "descrevia (para o filho pequeno) os encantos desse mundo de estranha beleza, do seu solo e de sua gente".

Creio que o convite the deveria ser feito. Que a Academia Brasileira de Letras deveria tomar conhecimento de modo o mais solene, do fato de que o autor de "A Montanha Mágica" descende de brasileira, de quem, em pequeno, ouviu historias de um Brasil que ainda não conhece senão de oitiva.

Um Rio Branco no Itamarati não se esqueceria de ligar o nome do Brasil ao nome de Thomas Mann. O mundo inteiro ficaria sabendo, pela voz das maiores agencias de publicidade, que o grande romancista era meiosangue brasileiro. Mann teria visitado o Brasil a convite do governo, Mann teria sido recebido aqui com banquete e com festas iguais àquelas com que se recebem reis e políticos, cardeais e chefes militares. Mann teria sido condecorado. Mann teria recebido as mais altas homenagens da Academia de Letras. Hoje, o que se vê? Thomas Mann passar dos setenta anos sem que o Brasil se tenha sequer lembrado de lhe prestar a homenagem especialíssima que ele merece receber dos brasileiros.

Daí meu apelo à Academia Brasileira de Letras. Que se movimente para promover a Mann a demonstração de particularíssimo afeto que ele já deveria ter recebido do Brasil. Pois é à Academia que toca, mais do que a nenhuma outra instituição brasileira, a iniciativa justa, ainda que tardia, de tal homenagem.

Que os redatores literarios dos jornais do Rio não vejam nesse meu apelo à mais alta das nossas associações literarias, nova disposição de minha parte para aproximar-me maciamente da Academia como um Romeu embuçado da sua doce Julieta; nem suponham que a idéia da homenagem a Mann seja apenas pretexto para a renovação do velho namoro, já descoberto por um bisbilhoteiro de idilios dessa especie - os idilios de individuos obscuros com instituições ilustres - em que eu estaria empenhado disfarçadamente, fingindo-me indiferente às honras acadêmicas.

O namoro, não digo que seja pura invenção dos bisbilhoteiros; talvez o seja. Inconcientemente talvez eu seja um velho namorado da Academia de Letras como sou um velho namorado da Igreja Católica de Roma. 
Paulino, S.; Soethe, P. - Thomas Mann e a cena intelectual no Brasil

Apenas esses namoros - não temam os rivais - são eternos namoros platônicos. Nenhum deles namoro para casar ou constituir família. Horrorizam-me não só os pais e os tios das duas noivas com os quais eu teria de conviver em família como a propria idéia de desapontar-me com a rotina do matrimonio, da convivencia cotidiana com uma academia ou uma igreja.

Daí minha atitude de cristão sempre fora das igrejas e de escritor sempre fora das academias, sem ser, entretanto, nem anti-católico nem antiacadêmico dentro de minha orientação de acatólico e de inacadêmico. Ao contrario: cada dia mais me convenço da conveniencia ou necessidade de tais organizações, compostas, é claro, de homens de vocação ortodoxa e de temperamento acadêmico acentuados e inconfundiveis. Igrejas e academias são particularmente uteis à saude moral e à disciplina intelectual de povos como o brasileiro, heterogeneos e inclinados à indisciplina. O Brasil intelectual estaria incompleto sem a sua Academia de Letras, como o mundo cristão estaria incompleto sem a Igreja de Roma - poderia dizer hoje um conselheiro Acacio que não temesse ser enfático na expressão do seu bom senso.

E porque a Academia é, ao meu ver, não uma escrecencia lamentavel nem um arcaismo ridiculo, mas, admitida uma exceção ou outra, instituição verdadeiramente representativa do que há de mais característico nas nossas tradições literariais, é que o recomendo aos senhores acadêmicos o caso de Thomas Mann: glorioso escritor, filho de brasileira, que não recebeu ainda do Brasil a homenagem excepcional que merece. Já que a Casa de Rio Branco não se preocupa hoje, como nos dias do Barão, com tais frivolidades, que se movimente a Casa de Machado de Assiz.

\section{Thomas Mann e o Brasil 10}

Tendo lido, graças a um amigo austríaco residente nesta capital - o jornalista e escritor Carlos de Lustig-Prean - o artigo de Gilberto Freyre "Thomas Mann, filho de brasileira", onde se sugere uma homenagem especial do Brasil e da Academia Brasileira de Letras ao grande romancista alemão, este manifestou-se a respeito em palavras que revelam sua simpatia pelos brasileiros. "O Apelo do prof. dr. Gilberto Freyre é de minha inteira e

10 Nota do jornal Folha da Manhã, em 25/04/1948, 3o Caderno.

Pandaemonium germanicum 14/2009.2, p. 28-53 - www.fflch.usp.br/dlm/alemao/pandaemoniumgermanicum 
Paulino, S.; Soethe, P. - Thomas Mann e a cena intelectual no Brasil

comovida satisfação etc. (Der appell des prof. dr. Gilberto Freyre hat mich mit Genugtuung erfullt und bewegt, etc."). Deste modo, pode-se ter como certo um movimento dentro e fora da Academia Brasileira de Letras, entre os intelectuais mais representativos do nosso país, que traga ao Brasil o glorioso autor de "A Montanha Mágica". O fato de ser Thomas Mann filho de brasileira, já fôra posto em relevo pelo escritor Gilberto Freyre no seu livro escrito em inglês "Brazil: an interpretation", que tem feito tanta repercussão nas Americas e na Europa, e no Brasil, onde apareceu sob o título de "Interpretação do Brasill", traduzido e prefaciado por Olivio Montenegro.

\section{Referências bibliográficas}

Adorno, T. W. Para um retrato de Thomas Mann. In: Notas de literatura. Rio de Janeiro, Tempo Brasileiro, 1972, 7-15.

BARTELS, Adolf. Jüdische Herkunft und Literaturwissenschaft: eine gründliche Erörterung. Leipzig, Verlag des Bartels-Bundes, 1925.

BRILL, Marte. Der Schmelztiegel. Frankfurt/M., Büchergilde Gutenberg, 2002.

CARneIro, Maria Luiza Tucci. Brasilien, Fluchtpunkt in den Tropen. Lebenswege der Flüchtlinge des Nazi-Faschismus. I Brasil, um refúgio nos trópicos. A trajetória dos refugiados do nazi-fascismo. São Paulo: Estação Liberdade, 1996.

Chacon, Vamireh. Thomas Mann e o Brasil. Rio de Janeiro, Tempo Brasileiro, 1975.

Elsaghe, Yahya. Thomas Mann und die kleinen Unterschiede. Zur erzählerischen Imagination des Anderen. Köln, Böhlau, 2004.

FLEMING, Peter. Brazilian adventure. Londres: Cape, 1933. (Ed. bras.: Uma aventura no Brasil. São Paulo: Marco Zero, 1996.)

HAMACHER, Gottfried. Gegen Hitler. Deutsche in der Résistance, in den Streitkräften der Antihlitlerkoalition und der Bewegung „Freies Deutschland“. Kurzbiografien. 2. ed. corr. Berlim: Dietz, 2005.

HolandA, Sérgio Buarque de. Thomas Mann e o Brasil. In: O espírito e a letra: estudos de crítica literária I. São Paulo, Companhia das Letras, 1976, 251-256.

JАСОВ, Heinrich Eduard. Estrangeiro. Der Fremdling. Ein Tropen-Roman. Frankfurt/ M.: Scheffler, 1951. 
Paulino, S.; Soethe, P. - Thomas Mann e a cena intelectual no Brasil

KeSTLER, Izabela Maria Furtado. Die Exilliteratur und das Exil der deutschsprachigen Schriftsteller und Publizisten in Brasilien. Frankfurt/M., Peter Lang, 1992.

Exílio e literatura: escritores de fala alemã durante a época do nazismo. São Paulo, EdUSP, 2004

KRÜLL, Marianne. Na rede dos Magos. Uma outra história da família Mann. Rio de Janeiro, Nova Fronteira, 1997.

KURZKE, Hermann. Thomas Mann: das Leben als Kunstwerk. München, Beck, 2000.

Kuschel, Karl-Josef; Mann, Frido; Soethe, Paulo Astor. Mutterland. Die Familie Mann und Brasilien. Düsseldorf, Artemis\&Winkler, 2009.

LoewensteIn, Karl. Brazil under Vargas. Nova York: Macmillian, 1942.

Lustig-Prean, Karl. Lustig-Preans lachendes Panoptikum. Frankfurt/M.; Viena: Forum, 1952.

MANN, Heinrich. Ein Zeitalter wird besichtigt. Frankfurt/M.: Fischer, 1988.

MAnN, Katia. Meine ungeschriebene Memoiren. Org. Elisabeth Plessen e Michael Mann. Frankfurt/M., Fischer, 1976.

MAnN, Thomas. Das Bild der Mutter. In: Über mich selbst. Autobiographische Schriften. Frankfurt/M., Fischer, 1983. p. 152-154.

. Briefe 1889-1955. Ed. p. Erika Mann. vol. I-III. Frankfurt/M.: Fischer, 1961ss. . Tagebücher. Frankfurt/M.: Fischer, 2003.

. Die Briefe Thomas Manns. Regesten und Register. Berab. und hrsg. v. Yvonne Schmidlin, Hans Bürgin, Hans Otto Mayer u. Gert Heine. 5. Bde. (I, 1976; II, 1980; III, 1982; IV, 1987; V, 1987). Frankfurt/M.: Fischer, 1976-1987.

Der Zauberberg (Gesammelte Werke). Peter de Mendelssohn (org.). 2a ${ }^{\mathrm{a}}$ ed. Frankfurt/M.: Fischer, vol. III, 1996.

. A montanha mágica. Rio de Janeiro, Nova Fronteira, 2000.

. A gênese do Doutor Fausto. Romance sobre um romance. São Paulo, Mandarim, 2001.

. Große kommentierte Frankfurter Ausgabe. Frankfurt/M.: Fischer, 2001-2009. (FA)

SCHNEIDER, Dieter Marc. Johannes Schauff, 1902-1990. Migration und 'Stabilitas' im Zeitalter der Totalitarismen. München, Oldenbourg Wissenschaftsverlag, 2001.

SoETHE, Paulo Astor. Deutsch, italienisch, brasilianisch: Heinrich Mann Zwischen den Rassen.In: Estudios Filológicos Alemanes (12), 2006a, Sevilla, 413-428.

. Thomas Mann: ironia burguesa e romantismo anticapitalista. In: CODATO, Adriano (Org.). Tecendo o Presente. Oito autores para pensar o século XX. Curitiba, SESC Paraná, 2006b. 
Paulino, S.; Soethe, P. - Thomas Mann e a cena intelectual no Brasil

StRAuSS, Dieter/ SENE, Maria A. (Orgs). Julia Mann: uma vida entre duas culturas. São Paulo, Estação Liberdade, 1997.

TORRESINI, Elizabeth Rochadel. História de um sucesso literário. Olhais os lírios do campo de Erico Verissimo. Porto Alegre, Literalis, 2003.

TrevisAn, João Silvério. Ana em Veneza. Best Seller, São Paulo, 1994.

Verissimo, Erico. Gato Preto em Campo de Neve. Porto Alegre, Editora Globo, 1961.

ZweIG, Stefan. Brasilien, ein Land der Zukunft. Stockholm, Bermann-Fischer, 1941. 